\title{
Antimicrobial stewardship: need of the hour
}

\author{
Razi Ahmad*, Sana Rehman
}

Department of Pharmacology, HIMSR, Jamia Hamdard, New Delhi, India

Received: 10 June 2018

Accepted: 03 July 2018

\section{*Correspondence to:}

Dr. Razi Ahmad,

Email: rahmad50@gmail.com

Copyright: (C) the author(s), publisher and licensee Medip Academy. This is an openaccess article distributed under the terms of the Creative Commons Attribution NonCommercial License, which permits unrestricted noncommercial use, distribution, and reproduction in any medium, provided the original work is properly cited.

\begin{abstract}
Efforts to tackle the global threat of Antimicrobial Resistance (AMR) have recently taken shape in a number of potentially far-reaching collaborative initiatives. When microbes become resistant to medicines, the options for treating the diseases they cause are reduced. This resistance to antimicrobial medicines is happening in all parts of the world for a broad range of microorganisms with an increasing prevalence that threatens human and animal health. The direct consequences of infection with resistant microorganisms can be severe, including longer illnesses, increased mortality, prolonged hospital stay, loss of protection for patients undergoing operations and other medical procedures, and increased costs. Antimicrobial resistance affects all areas of health, involves many sectors and has an impact on the whole of society. To overcome the threat of antimicrobial resistance, a three-pillar approach has been advocated i.e. Optimize the use of existing antimicrobial agents, prevent the transmission of drug-resistant organisms through infection control and Improve environmental decontamination. Antimicrobial stewardship [AMSP] is one of the key strategies to overcome resistance. It is an inter-professional effort, across the continuum of care, involves timely and optimal selection, dose and duration of an antimicrobial for the best clinical outcome for the treatment or prevention of infection with minimal toxicity to the patient and minimal impact on resistance and other ecological adverse events.
\end{abstract}

Keywords: Antimicrobial stewardship programme, Antimicrobial resistance, Antimicrobial

\section{INTRODUCTION}

Antimicrobial stewardship refers to a set of coordinated strategies to improve the use of antimicrobial medications by promoting the selection of the optimal antimicrobial drug regimen, dose, duration of therapy, and route of administration with the goal of enhancing patient health outcomes, reducing resistance to antibiotics, and decreasing unnecessary costs. ${ }^{1}$ The meaning of the term "antimicrobial stewardship" has evolved over the past decade. It was recently defined as a "coherent set of actions" that promote the responsible use of antimicrobials. The meaning of "responsible use" of antimicrobials is more difficult to define but generally refers to the goals of preventing or reducing antimicrobial resistance (AMR) and preserving the effectiveness of therapies for bacterial, viral, and fungal infections. Stewardship programmes aim to restrict inappropriate use of antibiotics, optimize selection, dose, route and duration of treatment for best outcomes, minimizing detrimental adverse events, excessive costs and emergence of resistance. Antimicrobial stewardship program (AMSP) is a hospital based program dedicated to improving antibiotic use, commonly referred to as AMSP have been found helpful in improving the quality of patient care and safety through increased infection cure rates, reducing treatment failures, and increasing the frequency of correct prescribing for therapy and prophylaxis but Antimicrobial stewardship programs (AMSPs) or strategies can apply to individual or population health, humans or animals, and 
the environment. ${ }^{2,3}$ The major objectives of antimicrobial stewardship are to achieve optimal clinical outcomes related to antimicrobial use, to minimize toxicity and other adverse events, and to limit the selection for antimicrobial resistant strains. Antimicrobial stewardship basically aims at helping patients receive safe and appropriate antibiotic and help in reducing treatment failures, reducing antibiotic resistance, and decreasing total cost of treatment and economic burden to the hospital and society.

\section{Why implement antimicrobial stewardship programme?}

The discovery of antibiotic treatments transformed healthcare, and dramatically improved our ability to reduce morbidity and mortality for all clinical areas, especially in surgery, transplant medicine, oncology and intensive care medicine. Yet, early medical practitioners and researchers soon discovered that bacteria exposed to antimicrobials quickly developed a resistance to those treatments. ${ }^{4}$

By 1968, researchers estimated that 50 percent of antimicrobial use was either unnecessary or inappropriate. ${ }^{5}$ Bacterial resistance to antibiotics has become an all pervading problem throughout the world and in India. ${ }^{6-9}$ Today, resistance to antimicrobial treatment is a critical issue, contributing to rapid spread of multiple organisms for which few treatments are available. The dramatic drop in the development and approval of new antibacterial agents and ever-increasing burden of infections caused by multi-drug resistant pathogen further complicates this global health problem and portends a future in which many more infections have no effective treatment option. ${ }^{10,11}$ The Centers for Disease Control and Prevention (CDC) estimates more than two million people are infected with antibiotic-resistant organisms, resulting in approximately 23000 deaths annually. ${ }^{12}$

Indian hospitals are facing an enormous challenge of managing multi-drug resistant organisms. The major threat is posed by gram negative bacteria which have not only become resistant to third generation cephalosporins, aminogycosides and fluroquinolones but also to carbapenems This situation has forced the clinicians to use colistin, tigecycline, fosfomycin in various combinations. ${ }^{13}$ One of the major contributing factors towards resistance has been antibiotic use. ${ }^{14}$ Antibiotic use has been seen to be high in India with one recent surveillance study indicating 40 per cent of patients in the community on antibiotics-and an even higher rate of inappropriate use. ${ }^{15,16}$

Antimicrobial resistance has emerged as a significant healthcare quality and patient safety issue in the twentyfirst century that, combined with a rapidly dwindling antimicrobial armamentarium, has resulted in a critical threat to the public health. One of the strategies to counter this would be to initiate antibiotic stewardship program. ${ }^{17}$ Therefore, antimicrobial stewardship must be a fiduciary responsibility for all healthcare institutions across the continuum of care.

\section{BASIC REQUIREMENT TO RUN AN ANTIMICROBIAL STEWARDSHIP PROGRAMME}

Implementation of an effective AMSP requires a multidisciplinary approach involving a variety of experts. The team involved in Antibiotic Stewardship consists of an infectious disease physician, clinical pharmacologist/pharmacist, clinical microbiologist, infection control nurse and hospital administrator. For AMSP to succeed, it is important to bring on board the various stakeholders in hospitals, especially the clinical pharmacologists. The discipline of clinical pharmacology needs to be involved in themes such as antimicrobial resistance and hospital infection which truly impact patient care. Clinical pharmacologists need to collaborate with faculty in other disciplines such as microbiology to achieve good outcomes for optimal patient care in the hospital setting. ${ }^{18,19}$ Easiest way to begin an AMSP is to make a team consisting of an administrative person, microbiologist, intensivist and a few clinical pharmacists (clinical pharmacologist). Daily post-prescriptive review of targeted antimicrobials should be done, Socioadaptive strategies included promoting culture change and empowering clinical pharmacist/ pharmacologist. The AMSP team will evaluate the appropriateness of antimicrobial administration, including loading and maintenance dose, frequency, route, duration of therapy, de-escalation and compliance with AMSP recommendations. Economic impact of AMSP should also be compared.

\section{Global scenario of antimicrobial stewardship programme}

Antibiotic stewardship and hospital infection control are two broad strategies which have been employed globally to contain the problems of resistance and infections. Development of antimicrobial resistance (AMR) in myriad groups of bacteria, fungi, viruses and parasites is a complex global health challenge. ${ }^{20}$ Newer classes of AMA is rapidly drying up, even though the use/abuse is increasing all over. ${ }^{21,22}$ An antimicrobial stewardship programme (2009-2014) in 47 South African hospitals led to a reduction in mean antibiotic defined daily doses per 100 patient days from 101.4 to $83.04 .^{23}$ In the US, infections with carbapenem resistant Enterobacteriaceae declined after the Antimicrobial Resistance Monitoring and Research Programme was started. In addition, there were no further reports of outbreaks caused by colistin resistant Acinetobacter spp. ${ }^{24}$ In the Netherlands, a decrease of CTX-M-1-1-like ESBL genes (from $44 \%$ to $25 \%$ ) in livestock was seen during 2010-14, possibly linked to considerable $(>60 \%)$ reduction in antibiotic use in livestock. ${ }^{25}$ "Antimicrobial Stewardship From Principles to Practice" an e-book released in March 2018, was published by the British Society for Antimicrobial Chemotherapy (BSAC), the European Society of Clinical 
Microbiology and Infectious Diseases (ESCMID) and the ESCMID Study Group for Antimicrobial Stewardship. This new ASP resource is available (with free registration) from the BSAC website. Its 27 chapters offer guidance on a wide range of topics regarding the goals and process of applying antimicrobial stewardship principles to various healthcare settings and patient populations, illustrated using case studies, narratives, journal articles, slide sets, and videos. ${ }^{26}$ A multidisciplinary team of experts in the UK have developed detailed evidence-based guidance on the treatment of infections due to multidrug-resistant (MDR) gram-negative bacteria. The new guidelines, devised by BSAC, the Healthcare Infection Society (HIS), and the British Infection Association (BIA), includes recommendations and best practices for antimicrobial prescribing, taking into account the challenges in optimizing antimicrobial therapy for MDR infections while also ensuring effective antimicrobial stewardship, particularly of the critical broad-spectrum agents. ${ }^{27}$

\section{Current scenario of antimicrobial stewardship activities in India}

India is among the world's largest consumers of antibiotics. $^{28}$ The five rapidly growing countries known as the BRICS (Brazil, Russia, India, China and South Africa) had the greatest upsurge in antibiotic use from 2000 through 2010; $(68 \%, 19 \%, 66 \%, 37 \%$, and $21 \%$ respectively). ${ }^{29}$ Although infection control guidelines and training programme had started relatively early. ${ }^{30}$ In India, Antimicrobial Stewardship programme, guidelines and training have lagged behind. The first global survey by Howard $\mathrm{P}$ et al, on implementation of antimicrobial stewardship activities worldwide reports $53 \%$ coverage in Asia. ${ }^{11}$ A survey of infection control programs in hospitals in India revealed that AMSP was not available in more than $50 \%$ of the hospitals. ${ }^{31}$

The Indian Council of Medical Research (ICMR), New Delhi, India, has launched the Anti-Microbial Resistance Surveillance and Research Network (AMRSN) across the country in 2013 with an avowed purpose of rationalizing AMSP in India. A survey conducted by a team of Indian Council of Medical Research in the yer-2013, on existing AMSP practices in the country to gauge ground realities and plug the loop holes and strengthen AMSP to understand the quality of infection control in 20 Government and private corporate hospitals found that while most of the hospitals have guidance document on infection control but the infrastructure required is often lacking in hospitals.

Similarly, the hospitals do not have standard treatment guidelines and even if they are present they are not strictly followed. The monitoring and audit of antimicrobial usage is rarity. ${ }^{32}$ Antimicrobial resistance and hospital infections have increased alarmingly in India. India is experiencing rising trends of antimicrobial resistance both in hospitals and communities mainly due to rampant overuse and misuse of antibiotics in situations where they are not needed. An effective infection control and antimicrobial stewardship program (AMSP) are pivotal in reducing the antimicrobial resistance burden in any hospital setting. India needs trained pharmacologists and microbiologists to address the need for Antibiotic Stewardship and Infection Control in various institutions and hospitals throughout India. The focus should be to bring together different disciplines and faculty in working towards a common cause, assessing the ground level realities in antibiotic use and hospital infections as well as developing strategic interventions through a collaborative approach to improve infection.

\section{Key challenges in implementing of antimicrobial stewardship in India}

Antibiotic stewardship programs (AMSP) have clear cut benefits in reducing the rate of inappropriate use of antibiotics but this is also not without limitations. ${ }^{33}$ More than $50 \%$ of hospitals in India do not have an AMS program. The common barriers identified for implementation of AMS were lack of funding and human resource, lack of information technology, lack of awareness of administration and last but not least prescriber opposition. Irrational and rampant use of antimicrobials (AMA) in animal farming and agriculture are equally important. Although the physicians recognize the challenges of antimicrobial resistance, these figures at the bottom of the list of factors influencing their choice of antibiotics, as the antibiotics are chosen for individual benefit. $^{34}$

The common barriers as identified by Howard P et al study in implementing AMSP were lack of funding and human resource, lack of information technology, lack of awareness of administration and prescriber opposition. ${ }^{11}$ Well dedicated and trained staff (pharmacologists and microbiologists) is the necessity of these programs that can devote sufficient amount of time in understanding the problem pathogens of the particular area and determine the priority areas and further implementing the plan of action along with rigorous monitoring. Lack of rapid Diagnostic Testing leading, another key challenge for antimicrobial stewardship is the development of new diagnostic methodologies that address the needs in low-resource settings, such as robust, inexpensive, and low-complexity tests implemented without centralized laboratory facilities, temperature-sensitive reagents, or trained personnel.

Automated or hand-held devices designed to deliver sample-to-answer results in less than an hour at the point of care as accurate and timely diagnosis provides the means to determine appropriate antimicrobial therapy. In low- and middle-income countries (LMICs), especially those with insufficient laboratory services, diagnostic and antimicrobial susceptibility testing is often unavailable, unreliable, or unaffordable. Accordingly, clinical management of suspected infection often starts with empiric antibiotic treatment as an easier or cheaper approach, contributing to the overuse of commonly 
available antibiotics, poor outcomes for many patients, and continued transmission of disease. Dealing with "Over the counter" availability of antimicrobials especially in developing countries: non-prescription use of antibiotics has a major contribution in escalating the danger of antibiotic resistance. ${ }^{35}$ This non-prescription use of drugs varies from $19 \%$ to $90 \%$ in various countries outside U.S. and Europe, which is a matter of serious concern and finally lack of awareness and support from physicians, and sometimes administrative shortsightedness are the major hurdles in efficient implementation of antimicrobial stewardship programme in all the developing countries including India.

\section{MEASURES FOR IMPROVEMENT IN ANTIMICROBIAL STEWARDSHIP PROGRAM}

Government must make Antimicrobial stewardship programme mandatory for all hospitals both government and private sector. Multi-stakeholder engagement and Public-private partnerships to offer refresher trainings, approved postgraduate certificate courses in AMSP will be helpful. Creating awareness among administrators by providing necessary information and organizing discussions and workshops. Making antimicrobial stewardship programme a core component of professional education, training, certification, continuing education and development in the health and veterinary sectors and agricultural practice will help to ensure proper understanding and awareness among professionals.

\section{ANTIMICROBIAL STEWARDSHIP RESEARCH}

Inviting investigators to submit research proposals focused on antimicrobial stewardship. Funds should be provided to conduct more research in all controversial aspects of AMSP so that better, easier and more effective strategies may be evolved and followed and those found less useful amended or even discarded. ${ }^{36-38}$

\section{At hospital level}

Every hospital either government and private sector must have:

- Antimicrobial stewardship programme that may follow either "front-end strategy" where antimicrobials are made available through an approval process (formulary restrictions and preauthorization) or "Back-end strategy" where antimicrobials are reviewed after antimicrobial therapy has been initiated (prospective audit with intervention and feedback to prescriber), proper written documentation on AMSP and frequent auditing must be performed to ascertain how well guidelines are followed.

- It has treatment guidelines and antimicrobial Prescribing Policy that is regularly reviewed and updated and antimicrobial usage data must be analyzed regularly.
- It has infection control guideline, Proper method for Collection and analysis of anti-Microbial resistance data of pathogens, Appropriate Collection of antimicrobial usage data, and appropriate monitoring and auditing mechanisms.

- It has a document which takes into account the regional data on antimicrobial resistance will thus help physicians in making relevant choices.

\section{Individual and community level}

Educating prescriber by training and workshops, providing Evidence based guidelines and Standard Antibiotic prescription chart, Handbooks and handouts with educational materials, restricting fixed-dose-combinations unless approved to be therapeutically beneficial and finally prescription auditing. Any policy to be successful requires community participation. Healthcare professional should commit themselves to explain the prescription to all the patients encountered. The community should be educated with respect to use of medicines only when prescribed by a qualified health care personnel, to complete the full prescription even if symptomatically cured, to never share antibiotics with others or use leftover prescriptions, to always follow up with the clinician to ensure complete cure. ${ }^{39}$ The public should be strictly discouraged from selfmedication practices and from availing and using drugs over-the-counter (OTC).

One of the major objective of AMSP is to decrease or restrict the use of certain antimicrobials which are supposed to impact the resistance more and allow dispensing of other drugs not presently associated with resistance. But, in this way we might be decreasing the pressure on one antibiotic by not using it but on the other hand we are giving opportunity to bacteria to acquire resistance to the currently available drugs. This phenomenon is referred as "squeezing the balloon". For example, in an ICU study, a heavy use of piperacillintazobactam was used with a high rate of piperacillin resistant Pseudomonas infections, in an attempt to decrease this resistance, piperacillin-tazobactam was replaced with imepenem. After some time, though the rate of piperacillin resistant Pseudomonas infections surely decreased, but it led to an increase in imepenem resistance. ${ }^{40}$

\section{CONCLUSION}

Stewardship programs are actually a boon to our health care society if implemented and monitored properly, Efficient Antimicrobial stewardship program results in sustainable long-term outcomes related to improved prescription practices for therapeutic and prophylactic purposes, improved quality of patient care, increased infection cure rates, reduced hospitalization rates, and reduced treatment costs, improved healthcare savings and a healthy human resource capital. These programmes have been shown to have both clinical and economic impact in hospitals. 
Funding: No funding sources

Conflict of interest: None declared

Ethical approval: Not required

\section{REFERENCES}

1. Dellit TH, Owens RC, McGowan JE, Gerding DN, Weinstein RA, Burke JP, et al. Infectious Diseases Society of America and the Society for Healthcare Epidemiology of America guidelines for developing an institutional program to enhance antimicrobial stewardship. Clinical Infectious Diseases. 2007 Jan 15;44(2):159-77.

2. Centres for Disease Control and Prevention (CDC). Core 7. elements of Hospital Antibiotic Stewardship Programs. Atlanta, GA: U.S. Department of Health and Human Services, CDC; 2014. Available at: http://www.cdc.gov/getsmart/healthcare/pdfs/coreelements.html. Accessed on August 19, 2014.

3. Dyar OJ, Huttner B, Schouten J. What is antimicrobial stewardship? Clin Microbiol Infect. 2017 Nov;23(11):793-8.

4. Fleming, Alexander. The Penicillin Finder Assays its Future. The New York Times; June 25, 1945:21.

5. Reimann HA, D'Ambola J. 30-50\% of antimicrobial use is either unnecessary or inappropriate. JAMA. 1968;205(7):537.

6. Gales AC, Jones RN, Turnidge J, Rennie R, Ramphal R. Characterization of Pseudomonas aeruginosa isolates: occurrence rates, antimicrobial susceptibility patterns, and molecular typing in the global SENTRY Antimicrobial Surveillance Program, 1997-1999. Clin Infect Dis. 2001;32(Suppl 2):S146-5. [PubMed]

7. Hoa NQ, Trung NV, Larsson M, Eriksson B, Phuc HD, Chuc NT, et al. Decreased Streptococcus pneumoniae susceptibility to oral antibiotics among children in rural Vietnam: a community study. BMC Infect Dis. 2010;10:85. [PMC free article] [PubMed]

8. Mathai E, Chandy S, Thomas K, Antoniswamy B, Joseph I, Mathai M, et al. Antimicrobial resistance surveillance among commensal Escherichia coli in rural and urban areas in Southern India. Trop Med Int Health. 2008;13:41-5. [PubMed]

9. Jain D, Sinha S, Prasad KN, Pandey CM. Campylobacter species and drug resistance in a north Indian rural community. Trans R Soc Trop Med Hyg. 2005;99:207-14. [PubMed]

10. Boucher HW, Talbot GH, Bradley JS, Edwards JE, Gilvert D, Rice LB, et al. Bad buds, no drugs: no ESKAPE! An update from the Infectious Diseases Society of America. Clinical Infectious Disease. 2009;48:1-12.

11. Biomerieux. Practical guide to Antimicrobial Stewardship in hospitals. Biomerieux, France; 2013:4.

12. Centers for Disease Control and Prevention. Core elements of antibiotic stewardship programs. Available at: http://www.cdc.gov/getsmart/healthcare/implementat ion/core-elements.html.
13. Lenhard JR. Nation RL and Tsuji BT. Synergistic combinations of Polymyxins. Int J Antimicrob Agents. 2016;48(6):607-13.

14. Goossens H, Ferech M, Vander Stichele R, Elseviers $M$ ESAC Project Group. Outpatient antibiotic use in Europe and association with resistance: a crossnational database study. Lancet. 2005;365:579-87. [PubMed]

15. Chandy SJ, Thomas K, Mathai E, Antonisamy B, Holloway KA, Stalsby LC. Patterns of antibiotic use in the community and challenges of antibiotic surveillance in a lower-middle-income country setting: a repeated cross-sectional study in Vellore, South India. J Antimicrob Chemother. 2013;68:22936. [PubMed]

16. Kumari IS, Chandy SJ, Jeyaseelan L, Kumar R, Suresh S. Antimicrobial prescription patterns for common acute infections in some rural and urban health facilities of India. Indian J Med Res. 2008;128:165-71. [PubMed]

17. Dellit TH, Owens RC, McGowan JE, Jr, Gerding DN, Weinstein RA, Burke JP, et al. Infectious Diseases Society of America and the Society for Healthcare Epidemiology of America guidelines for developing an institutional program to enhance antimicrobial stewardship. Clin Infect Dis. 2007;44:159-77. [PubMed]

18. Centres for Disease Control and Prevention (CDC). Core 7. elements of Hospital Antibiotic Stewardship Programs. Atlanta, GA: U.S. Department of Health and Human Services, CDC; 2014. Available at: http://www.cdc.gov/getsmart/healthcare/pdfs/coreelements.html, accessed on August 19, 2014.

19. Chandy SJ, Michael JS, Veeraraghavan B, Abraham OC, Bachhav SS, Kshirsagar NA. ICMR programme on antibiotic stewardship, prevention of infection \& control (ASPIC). Ind J Med Resea. 2014 Feb;139(2):226.

20. World Heath Organization (WHO). Antimicrobial resistance: global report on surveillance. Geneva: WHO; 2014.

21. Howard SJ, Catchpole M, Watson J, Davies SC. Antibiotic 2. resistance: global response needed. Lancet Infect Dis. 2013;13:1001-3.

22. Laxminarayan R, Duse A, Wattal C, Zaidi AK, Wertheim HF, Sumpradit N, et al. Antibiotic resistance- the need for global solutions. The Lancet infectious diseases. 2013 Dec 1;13(12):1057-98.

23. Brink AJ, Messina AP, Feldman C, Richards GA, Becker PJ, Goff DA, et al. Antimicrobial stewardship across 47 South African hospitals: an implementation study. The Lancet Infectious Diseases. 2016 Sep 1;16(9):1017-25.

24. Lesho EP, Waterman PE, Chukwuma U, McAuliffe K, Neumann C, Julius MD, et al. The antimicrobial resistance monitoring and research (ARMoR) program: the US Department of Defense response to escalating antimicrobial resistance. Clinical Infectious Diseases. 2014 May 1;59(3):390-7. 
25. Willemsen I, Oome S, Verhulst C, Pettersson A, Verduin K, Kluytmans J. Trends in extended spectrum beta-lactamase (ESBL) producing Enterobacteriaceae and ESBL genes in a Dutch teaching hospital, measured in 5 yearly point prevalence surveys (20102014). PLoS One. 2015;358:e0141765.

26. Lesho EP, Waterman PE, Chukwuma U, McAuliffe K, Neumann C, Julius MD, et al. The antimicrobial resistance monitoring and research (ARMoR) program: the US Department of Defense response to escalating antimicrobial resistance. Clinical Infectious Diseases. 2014 May 1;59(3):390-7.

27. Hawkey PM, Warren RE, Livermore DM, McNulty CA, Enoch DA, Otter JA, et al. Treatment of infections caused by multidrug-resistant Gram-negative bacteria: report of the British Society for Antimicrobial Chemotherapy/healthcare Infection Society/british Infection Association Joint Working Party. J Antimicrob Chemother. 2018 Mar 1;73(3):iii2-78.

28. Laxminarayan R, Chaudhury RR. Antibiotic resistance in India: drivers and opportunities for action. PLoS Med. 2016;358:e1001974.

29. Van Boeckel TP, Gandra S, Ashok A, Caudron Q, Grenfell BT, Levin SA, et al. Global antibiotic consumption 2000 to 2010: an analysis of national pharmaceutical sales data. Lancet Infect Dis. 2014;14(8):742-50.

30. Rattan A, Bhujwala RA, Kumar RS. Organization of infection control program. J Acad Hosp Adm. 1992;4:21-5. [PubMed].

31. Sureshkumar D, Gopalakrishnan R, Ramasubramanian V. Survey of infection control programs in India. Poster presentation in ID week; October 2013:2-6. San Francisco. Available at: https://idsa.confex.com/idsa/2013/webprogram/Paper 42 762.html.

32. Walia K, Ohri VC, Mathai D. Antimicrobial stewardship programme (AMSP) practices in India. Ind J Med Resear. 2015 Aug;142(2):130.
33. Doron S, Davidson LE. Antimicrobial stewardship. Mayo Clin Proc. 2011;86(11):1113-23.

34. Giblin TB, Sinkowitz-Cochran RL, Harris PL, Jacobs S, Liberatore K, Palfreyman MA, et al. Clinicians' perceptions of the problem of antimicrobial resistance in health care facilities. Archives of internal medicine. 2004 Aug 9;164(15):1662-8.

35. Morgan DJ, Okeke IN, Laxminarayan R, Perencevich EN, Weisenberg S. Non-prescription antimicrobial use worldwide: a systematic review. Lancet Infect Dis. 2011;11(9):692-701.

36. Hranjec T, Rosenberger LH, Swenson W, Metzqer R, Flohr TR, Politano AD, et al. Aggressive versus conservative initiation of antimicrobial treatment in critically ill surgical patients with suspected intensivecare-unit-acquired infections: a quasi-experimental, before and after observational cohort study. Lancet Infect Dis. 2012;12:774-80.

37. Pronovost P, Needham D, Berenholtz S, Sinopoli D, Chu H, Cosgrove S, et al. An intervention to decrease catheter-related blood stream infections in the ICU. N Engl J Med. 2006;355:2725-32.

38. Weber DJ, Anderson D, Rutala WA. The role of the surface 19. environment in healthcare-associated infections. Curr Opin Infect Dis. 2013;26:338-44.

39. World Health Organization (WHO). Antimicrobial resistance- Global report on surveillance. WHO Press; 2014. Available at: http://apps.who.int/iris/bitstream /10665/112642/1/9789 241564748_eng.pdf?ua=1.

40. Allegranzi B, Luzzati R, Luzzani A, Girardini F, Antozzi L, Raiteri R, et al. Impact of antibiotic changes in empirical therapy on antimicrobial resistance in intensive care unit-acquired infections. Journal of Hospital Infection. 2002 Oct 1;52(2):13640 .

Cite this article as: Razi A, Rehman S.

Antimicrobial stewardship: need of the hour. Int J Basic Clin Pharmacol 2018;7:1444-9. 